\title{
Effects of green tea polyphenol on methylation status of RECK gene and cancer cell invasion in oral squamous cell carcinoma cells
}

\author{
K Kato*, I,3, NK Long',3 ${ }^{1,3}$ Makita', M Toida', T Yamashita', D Hatakeyama', A Hara ${ }^{2}$, H Mori' ${ }^{2}$ and T Shibata' \\ 'Department of Oral and Maxillofacial Sciences, Gifu University, Graduate School of Medicine, I-I Yanagido, Gifu 50 I- I 194, Japan; ${ }^{2}$ Department of \\ Tumor Pathology, Gifu University, Graduate School of Medicine, Gifu 50 I- I 194, Japan
}

\begin{abstract}
RECK is a novel tumour suppressor gene that negatively regulates matrix metalloproteinases (MMPs) and inhibits tumour invasion, angiogenesis and metastasis. In the present study, we investigated the effects of epigallocatechin-3-gallate (EGCG), a major polyphenol in green tea, on the methylation status of the RECK gene and cancer invasion in oral squamous cell carcinoma cell lines. Our results showed that treatment of oral cancer cells with EGCG partially reversed the hypermethylation status of the RECK gene and significantly enhanced the expression level of RECK mRNA. Inhibition of MMP-2 and MMP-9 levels was also observed in these cells after treatment with EGCG. Interestingly, EGCG significantly suppressed cancer cell-invasive ability by decreasing the number of invasive foci $(P<0.000 \mathrm{I})$ as well as invasion depth $(P<0.005)$ in three-dimensional collagen invasion model. Although further investigation is required to assess the extent of contribution of RECK on MMPs to the suppression of invasive behaviour, these results support the conclusion that EGCG plays a key role in suppressing cell invasion through multiple mechanisms, possibly by demethylation effect on MMP inhibitors such as RECK.
\end{abstract}

British Journal of Cancer (2008) 99, 647-654. doi:I0.1038/sj.bjc.660452 I www.bjcancer.com

Published online 29 July 2008

(C) 2008 Cancer Research UK

Keywords: green tea polyphenol; EGCG; RECK hypermethylation; oral cancer invasion

Cancer development is a multistage process requiring progressive genetic and epigenetic changes in neoplastic and responding stromal cells. During the process of malignant progression, migration of cells into the underlying extracellular matrices is a fundamental feature of tumour invasion. The reversion-inducing cysteine-rich protein with Kazal motifs (RECK), a novel matrix metalloproteinases (MMPs) inhibitor, was originally isolated as a transformation suppressor gene against activated ras oncogenes (Takahashi et al, 1998; Oh et al, 2001; Sasahara et al, 2002; Noda et al, 2003; Simizu et al, 2005; Chang et al, 2006). Previous studies have revealed that $R E C K$ is able to inhibit tumour angiogenesis, invasion, and metastasis. Its downregulation has been shown in several types of human cancers. Recently, the decrease in $R E C K$ expression is reported to correlate with hypermethylation of the promoter region (Furumoto et al, 2000; Song et al, 2006; Chang et al, 2007; Cho et al, 2007). In human cancers, aberrant methylation of tumour suppressor genes is of comparable significance to classic genetic mutations (Lund and van Lohuizen, 2004; Ha and Califano, 2006; Stresemann et al, 2006; Shaw, 2006). The study of the patterns of gene silencing because of hypermethylation would therefore help to understand and predict cancer cell behaviour and responsiveness to various treatments of cancers (Hellebrekers et al, 2007; Shaw et al, 2007).

Tea is the most widely consumed beverage worldwide. Tea components, especially green and black tea constituents, have been reported to prevent carcinogenesis in vitro and in vivo (Jung and Ellis, 2000; Benelli et al, 2002; Yang et al, 2002; Chung et al, 2003;

\footnotetext{
*Correspondence: Dr K Kato; E-mail: keizo@gifu-u.ac.jp

${ }^{3}$ These authors contributed equally to this work.

Received 9 November 2007; revised 23 June 2008; accepted 30 June 2008; published online 29 July 2008
}

Fang et al, 2003; Fassina et al, 2004; Ju et al, 2005; Khan et al, 2006). Epigallocatechin-3-gallate (EGCG), the major polyphenol in green tea, is believed to be a key active ingredient. Previous studies have shown that EGCG is methylated by catechol-O-methyltransferase and inhibits DNA methyltransferase (DNMT). The inhibition of DNMT would block the hypermethylation of the newly synthesised DNA strand, resulting in the reversal of the hypermethylation and the re-expression of the silenced genes (Fang et al, 2003; Lund and van Lohuizen, 2004; Ha and Califano, 2006; Stresemann et al, 2006; Shaw, 2006; Hellebrekers et al, 2007; Shaw et al, 2007). Other DNMT inhibitors such as 5-aza$2^{\prime}$-deoxycytidine (5-aza-dC) and zebularine also have similar inhibitory effect. Although there is a high potential for developing this group of inhibitors for cancer therapy, side effects and toxicity are serious concerns. The chemoprevention of cancer by tea components as natural inhibitors of DNMT is therefore such a promising approach with less side effects and toxicity (Chung et al, 2003; Lambert and Yang, 2003; Szyf et al, 2004; Ju et al, 2005; Wilson et al, 2007).

In the present study, we determined the effects of EGCG treatment on the methylation status and expression level of the RECK gene in human oral squamous cell carcinoma cell lines. The inhibition of oral carcinoma invasion by EGCG was also examined by a three-dimensional collagen invasion model.

\section{MATERIALS AND METHODS}

\section{Cell lines and cell cultures}

Four human oral squamous cell carcinoma cell lines HSC3, HSC4, SCC9, SCC25 and human cervical cancer cell line HeLa were examined. These cell lines were obtained from Cell Resource 
Center for Biomedical Research (Tohoku University, Sendai City, Japan). All cell lines were maintained in RPMI-1640 (SigmaAldrich Company, St. Louis, MO, USA) supplemented with $10 \%$ fetal bovine serum (FBS) (Life Technologies Inc., Gaithersburg, $\mathrm{MD}, \mathrm{USA}$ ) and $50000 \mathrm{U}$ penicillin, $50 \mathrm{mg}$ streptomycin at $37^{\circ} \mathrm{C}$ in a $5 \% \mathrm{CO}_{2}$ humidified atmosphere. The cancer cell lines were also cultured in medium with $50 \mu \mathrm{M}$ EGCG (Wako Pure Chemical Industries, Ltd., Osaka, Japan) or $8.7 \mu \mathrm{M}$ 5-aza-dC (MP Biomedicals, LLC, Eschwege City, Germany) for 6 days and harvested for further analyses as previously described (Fang et al, 2003). To determine the dose-dependent changes, SCC 9 and HSC3 cell lines were treated with $5,10,20$, or $50 \mu \mathrm{m}$ of EGCG or $8.7 \mu \mathrm{M}$ of 5 -aza-dC for 6 days. EGCG or 5-aza-dC was added, in new culture medium, to the cells on days 1,3 , and 5 . For the time course study, the cells were treated with $50 \mu \mathrm{M}$ of EGCG for 36,72 , or $144 \mathrm{~h}$.

\section{Bisulphite modification and methylation-specific PCR}

One microgram of the purified DNA was subjected to bisulphite modification. Bisulphite modification was performed using CpGenome $^{\mathrm{TM}}$ DNA Modification Kit (Chemicon International, Temecula, CA, USA) according to the manufacturer's instructions. For MSP, the following primer sets were used: for methylated DNA, MF_RECK (5'-GTTAGTTTTTTTTTTTATTTTAGTGGTTCGA-3') and MR_RECK (5'-TCCAAAACCTCCCGAAAACGAAAACG- $\left.3^{\prime}\right)$, and for unmethylated DNA, UF_RECK (5'-GGTTAGTTTTTTTT TTTATTTTAGTGGTTTGA- $\left.3^{\prime}\right)$ and UR_RECK $\left(5^{\prime}\right.$-ATTTCCAAAA CCTCCCAAAAACAAAAACA- $\left.3^{\prime}\right)$. Reactions were performed in $20 \mu \mathrm{l}$ volumes under the following conditions: $95^{\circ} \mathrm{C}$ for $10 \mathrm{~min}$; then 40 cycles of $95^{\circ} \mathrm{C}$ for $30 \mathrm{~s}, 56^{\circ} \mathrm{C}$ for $30 \mathrm{~s}$, and $72^{\circ} \mathrm{C}$ for $30 \mathrm{~s}$; and finally $7 \mathrm{~min}$ at $72^{\circ} \mathrm{C}$. The PCR product lengths for methylated and unmethylated RECK are 201 and $205 \mathrm{bp}$. CpGenome Universal Methylated DNA (Serologicals, Atlanta, Georgia, USA) and normal human blood DNA was used as positive control for methylated and unmethylated status. Water blank was used as a negative control. Positive and negative controls worked appropriately in each round of PCR. All assays were performed in triplicate.

\section{Reverse transcription-PCR and quantitative real-time PCR}

Total RNA was isolated from $10^{5}$ to $10^{6}$ cultured cells using a Trizol reagent kit (Invitrogen, Carlsbad, CA, USA). cDNA was synthesised from $1 \mu \mathrm{g}$ of total RNA using MMLV Reverse Transcriptase (Invitrogen) with random hexamers. RECK cDNA was amplified by PCR using the sense primer $5^{\prime}$-GCAGGGGAAGTTGGTTGTTA- $3^{\prime}$ and antisense primer $5^{\prime}$-TGCCAGCAAAACAAGAACAG-3'. Reactions were performed in $20 \mu \mathrm{l}$ volumes under the following conditions: $95^{\circ} \mathrm{C}$ for $10 \mathrm{~min}$; then 35 cycles of $95^{\circ} \mathrm{C}$ for $30 \mathrm{~s}, 60^{\circ} \mathrm{C}$ for $30 \mathrm{~s}$, and $72^{\circ} \mathrm{C}$ for $30 \mathrm{~s}$; and finally $7 \mathrm{~min}$ at $72^{\circ} \mathrm{C}$. Glyceraldehyde-3-phosphate dehydrogenase (GAPDH) was used as an internal control to estimate the efficiency of the cDNA synthesis in each cell line with forward primer: $5^{\prime}$-AGCATCTACACCTGAGGA

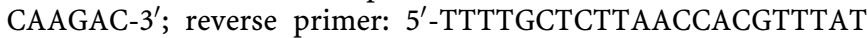
TGA-3'. The integrated optical density of each band was quantified by densitometry. The relative levels of RECK mRNA were normalised against the GAPDH.

Quantitative real-time PCR assay was performed using SYBR ${ }^{\circledR}$ Premix Ex Taq ${ }^{\mathrm{TM}}$ in Thermal Cycler Dice ${ }^{\mathbb{R}}$ (Takara, Tokyo, Japan). The cycling conditions were initial denaturation at $95^{\circ} \mathrm{C}$ for $10 \mathrm{~s}$, and 40 cycles at $95^{\circ} \mathrm{C}$ for $5 \mathrm{~s}, 60^{\circ} \mathrm{C}$ for $30 \mathrm{~s}$ according to the SYBR ${ }^{\circledR}$ Premix Ex Taq (Perfect Real Time) protocol. Second derivative maximum method was used to calculate the $C_{\mathrm{t}}$ (threshold cycle) value and standard curve method was used for relative quantification analysis. The $C_{\mathrm{t}}$ value of RECK was normalised by the $C_{\mathrm{t}}$ of GAPDH in the same sample. Each reaction was run in triplicate.

\section{Gelatin zymography}

Cancer cell lines were seeded in bio-coat culture disks (Becton Dickinson Labware, Bedford, MA, USA) for 6 days. Fresh medium without FBS was replaced $24 \mathrm{~h}$ before analysis. MMP-2 and MMP-9 enzymatic activity in cancer cell lines was determined by sodium dodecyl sulphate (SDS) polyacrylamide gel electrophoresis (PAGE) gelatin zymography as described in our previous study (Kato et al, 2005). In brief, the gelatinolytic activity was measured in the presence of both proforms and activated forms of the MMP-2 and MMP-9. The cell extract was diluted in the ratio of $1: 1$ with sample buffer (TEFCO, Tokyo, Japan) and left at room temperature for $10 \mathrm{~min}$. The cell extracts were applied to SDS-PAGE using a $10 \%$ gel containing $0.1 \%$ gelatin. After electrophoresis the gel was rinsed with renaturing buffer (TEFCO) for $30 \mathrm{~min}$, and the gel was incubated in developing buffer (TEFCO) for $48 \mathrm{~h}$ at $37^{\circ} \mathrm{C}$. After incubation the gel was stained with $0.05 \%$ Coomassie brilliant blue R250 (Wako Pure Chemical Industries, Osaka, Japan). The MMPs were detected as transparent bands on the blue background of the Coomassie blue stained slab gel.

\section{Collagen gel invasion model}

Collagen gels were used as matrices for cancer cell invasion and prepared according to the method of Hase et al (2006) with a little adjustment. Type I collagen (Nippon Meat Packers Inc., Osaka, Japan) was mixed with medium and $\times 10 \mathrm{PBS}$ at a ratio of $1: 1: 8$ and air-vacuumed for $30 \mathrm{~min}$ before incubated in $5 \% \mathrm{CO}_{2}$ and $37^{\circ} \mathrm{C}$ until gelling was completed. Cancer cells $\left(3 \times 10^{5}\right)$ from each cell line were seeded on the collagen gels in medium with and without EGCG or 5-aza-dC. The cancer cells were maintained at $5 \% \mathrm{CO}_{2}$ atmosphere and $37^{\circ} \mathrm{C}$ for 7 and 14 days. The collagen gel was collected and fixed in $10 \%$ formalin, embedded in paraffin, stained with haematoxylin and eosin and examined for cancer cell invasion.

\section{Assays for cell invasion and migration}

Cell invasion and immigration assays were used to assess the formation of invasive foci and the depth of cell invasion into the collagen matrix previously described by Hotary et al (2000) and Liebersbach and Sanderson (1994). Six days after the addition of cells to gels, invasive foci were counted in randomly selected fields at $\times 200$ magnification on phase-contrast microscope. The depth of cell invasion was determined by measuring the distance from the top of the gel to the leading front of migrating cells. The leading front distance was defined as the point at which two of the most distantly migrating cancer cells were simultaneously in focus in one field under $\times 200$ magnification. Measurements were made using the calibrated micrometer of a Nikon inverted microscope. Measurements were taken in five fields within each well, and the mean distance was determined.

To measure cell proliferation rates, $8 \times 10^{4}$ cells were placed into each culture plate and cultured for 3, 5, 7 days in medium without and with $50 \mu \mathrm{m}$ EGCG and $8.7 \mu \mathrm{m} 5$-aza-dC. At each time point, the cells were harvested by trypsinisation and counted using a hemacytometer.

Cell migration ability was assessed by seeding $2-5 \times 10^{5}$ cells atop collagen gels with surfaces partially covered by glass coverslips $(1 \times 2 \mathrm{~cm}$; Matsunami Glass Ind, Ltd., Osaka, Japan $)$. When the cells reach confluence, the glass fragments were removed, leaving a cell-free area on the gel. At this time, medium was added to all cultures in the absence or presence of EGCG and 5 -aza-dC. The distances migrated across the gels were observed $24 \mathrm{~h}$ later using an inverted microscope. 


\section{Statistical analysis}

Differences between treatment and control groups were assessed by analysis of variance with post hoc test (Dunnett's test). Statistical analyses on the invasive foci and depth of invasion of the cancer cell lines were performed using the Student's $t$-test. The results were considered statistically significant at $P<0.05$.

\section{RESULTS}

Methylation status and expression of the RECK gene in OSCC cell lines

A hypermethylated RECK promoter was observed in all four OSCC cell lines $(100 \%)$ by MSP. SCC9 and SCC25 cell lines contained both unmethylated and methylated promoters whereas HSC4 and HSC3 cell lines had strongly methylated promoter and faintly unmethylated promotor. Methylation of RECK gene was not detected in HeLa cancer cell line whereas its unmethylationspecific band appeared as a weak band (Figure 1A). The expression levels of RECK mRNA in 4 human oral cancer cell lines and HeLa were examined by RT - PCR. The results showed that the HSC3 and HSC4 cell lines expressed very low RECK mRNA levels. SCC9 and SCC25 cells had downregulated expression whereas HeLa produced a normal amount of RECK mRNA (Figure 1A).

\section{Reversal of hypermethylation status and enhanced expression of RECK gene in OSCC cell lines by EGCG}

To evaluate whether methylation status of RECK promoter is associated with transcriptional downregulation of $R E C K$ gene in the OSCC cell lines, demethylation treatment by 5 -aza-dC and EGCG were performed on the OSCC cell lines. In all cancer cell lines, the RECK gene had hypermethylation status with the low level of the respective mRNA expression. The appearance of unmethylation-specific bands of RECK gene in all four cancer cell lines became more intense after treatment with $50 \mu \mathrm{M}$ EGCG or $8.7 \mu \mathrm{M} 5$-aza-dC for 6 days. Treatment of SCC9 and HSC3 with EGCG and 5-aza-dC for 6 days also enhanced the transcription of RECK mRNA whereas RECK mRNA level was not significantly altered in HSC4 and SCC25 after treatment with EGCG (Figure 1B).

We examined the time-dependent and dose-dependent effects of EGCG in SCC9 and HSC3 cell lines. After treating cells with 5, 10, 20 , or $50 \mu \mathrm{M}$ of EGCG for 6 days, the methylation-specific bands of this gene still existed but in a weak appearance. The unmethylation-specific bands of RECK gene, however, appeared to be enhanced after treatment with 20 or $50 \mu \mathrm{M}$ of EGCG for 6 days. Corresponding to the appearance of the unmethylation-specific band was the increase of expression of RECK mRNA by conventional RT-PCR. The unmethylation-specific bands and mRNA expression were significantly stronger with $50 \mu \mathrm{M}$ of EGCG in comparison with those treated with $20 \mu \mathrm{M}$ EGCG or lower concentrations $(P<0.01)$. The reversal of hypermethylation and increase of expression of RECK by EGCG were almost similar to that produced by the classical DNMT inhibitor, 5-aza-dC. After treating the cells with $50 \mu \mathrm{M}$ of EGCG for 36,72 , and $144 \mathrm{~h}$, strong unmethylation-specific bands of the RECK gene began to appear at $72 \mathrm{~h}$. The higher level of mRNA expression of RECK was also observed at 72 and $144 \mathrm{~h}(P<0.01)$ (Figure 2$)$.

To confirm the effect of EGCG on RECK expression, real-time quantitative PCR was performed to determine the mRNA expression level of RECK gene in HSC3 and SCC9 cell lines after treatment with different concentrations of EGCG. The results showed that the relative amount of mRNA expression of RECK was increased in a dose- and time-dependent manner with significant effect at 20 and $50 \mu \mathrm{M}$ EGCG $(P<0.01$ and $P<0.001)$ and at 72 and $144 \mathrm{~h}(P<0.01$ and $P<0.001)$. This result was generally consistent with those from general reverse transcription-PCR, however, with a significant effect at lower concentration of EGCG $(20 \mu \mathrm{M})$ (Figure 3).

A
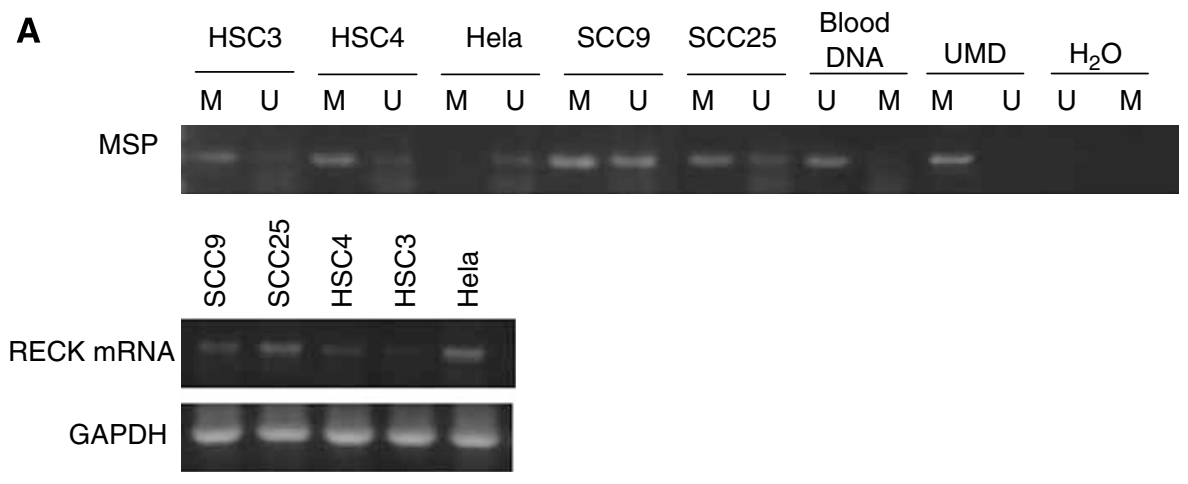

B
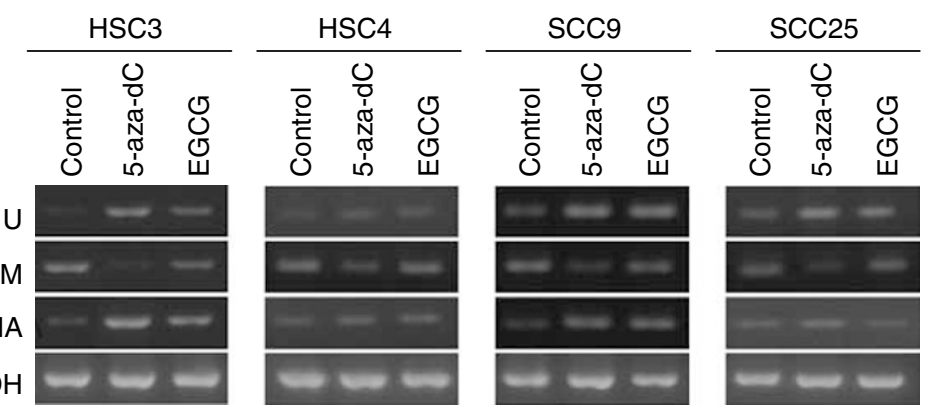

Figure I Methylation status and mRNA expression levels of the RECK gene. (A) Methylation analysis of the RECK promoter and mRNA expression in OSCC and HeLa cell lines. M, Methylation-specific band; U, Unmethylation-specific band; Blood DNA, normal human blood DNA as positive control for unmethylated status; UMD, Universal methylated DNA as positive control for methylated status; H20, Negative control. (B) Alterations of methylation status and mRNA expression levels of the RECK gene in OSCC cell lines after treatment with $50 \mu \mathrm{M}$ EGCG or $8.7 \mu \mathrm{M} 5$-aza-dC for 6 days. GAPDH was used as an internal control. 


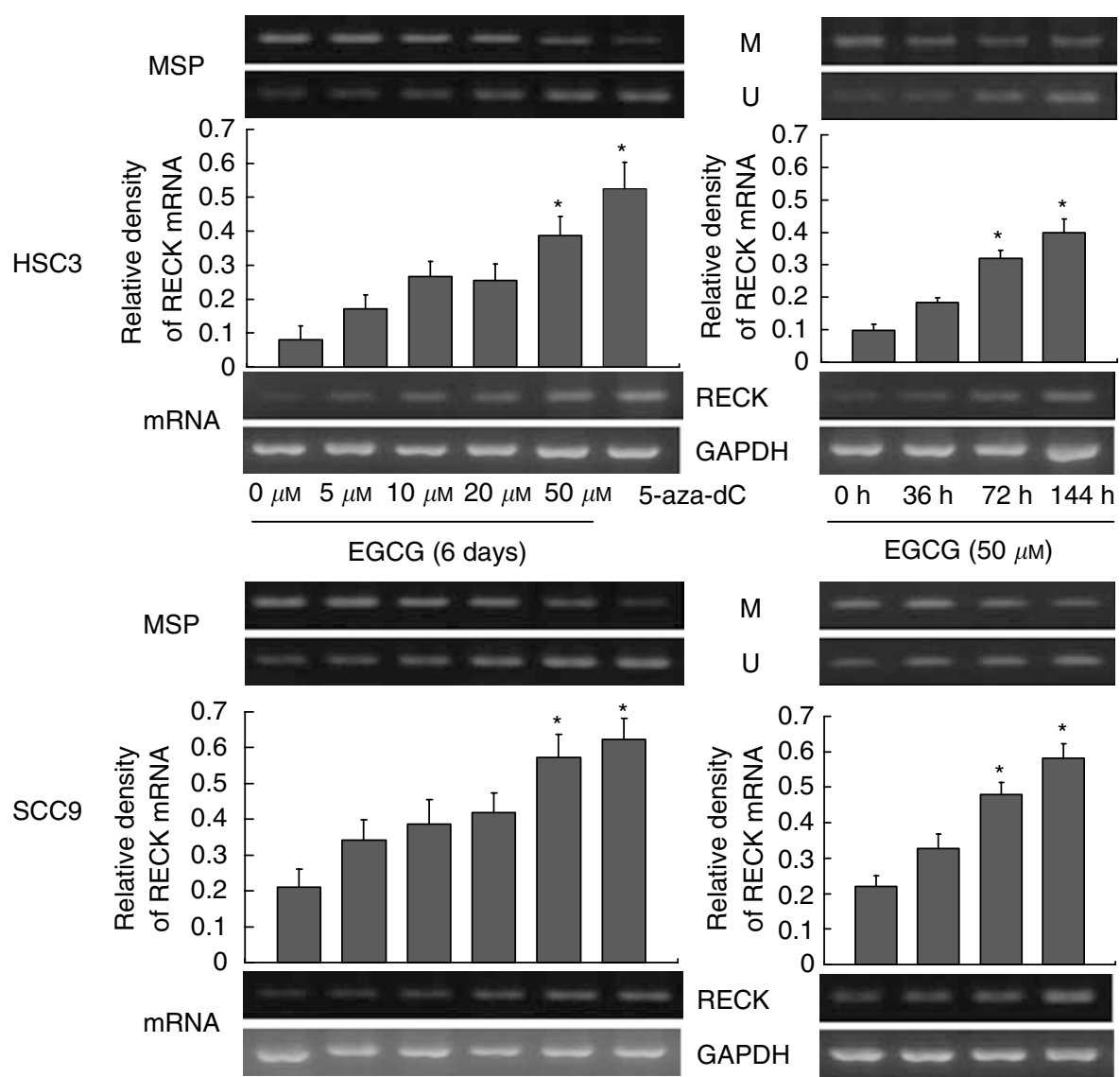

Figure 2 Dose-dependent and time course study. SCC9 and HSC3 cells were treated with 5, 10, 20, or $50 \mu \mathrm{M}$ EGCG or $8.7 \mu \mathrm{M} 5$-aza-dC for 6 days. Cell lines were treated for 32, 72, and $144 \mathrm{~h}$ with $50 \mu \mathrm{M}$ of EGCG. The relative levels of RECK mRNA were normalised to the GAPDH. Band density was determined with densitometry. The bars represent mean \pm s.d. $(n=3)$. $* P<0.0$ I when compared with control.

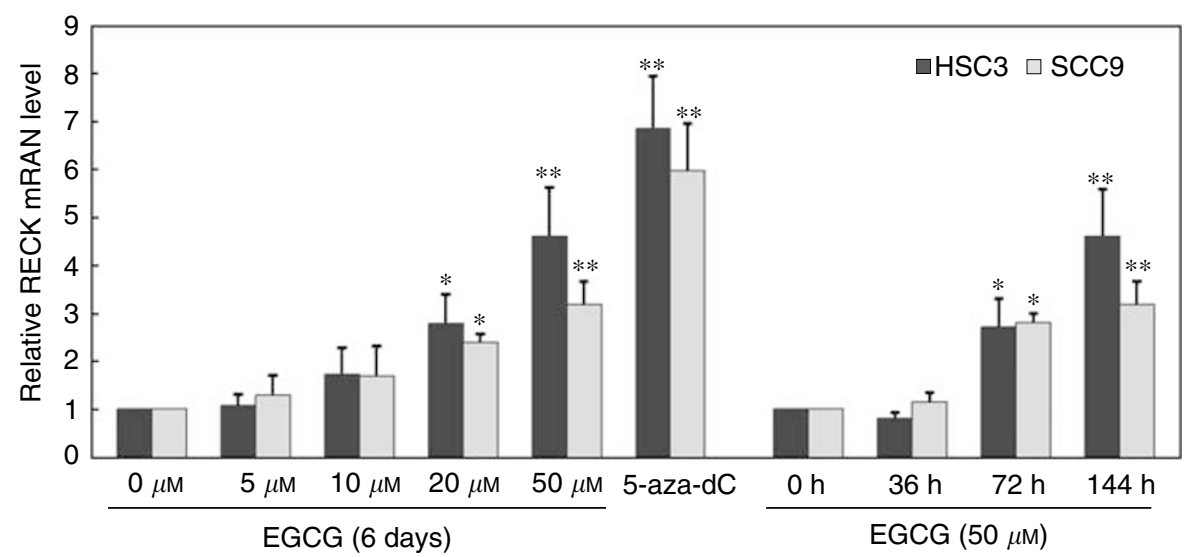

Figure 3 Relative mRNA expression levels of RECK gene by quantitative real-time PCR in HSC3 and SCC9 cell lines. EGCG enhanced RECK mRNA expression in a dose- and time-dependent manner. Expression levels were normalised to the human GAPDH control gene, an endogenous control. All expression levels are shown relative to the untreated sample. The bars represent mean \pm s.d. $(n=3)$. $* P<0.0$ I; $* * P<0.00$ I when compared with control.

\section{Downregulation of MMPs by EGCG}

Gelatin zymography results showed that MMP-2 and MMP-9 expression and activity were suppressed in SCC9 and HSC3 cells treated with EGCG and 5-aza-dC for 6 days (Figure 4). Culture with EGCG or 5-aza-dC decreased total MMP-2 levels and downregulated the activation of proMMP-2. Although proMMP-9 was detectable, active forms of MMP- 9 were not readily observed in this experiment. Treatment with $50 \mu \mathrm{M}$ EGCG did not cause downregulation in MMP-9 activity but MMP-2 in HSC4 and SCC25 cancer cell line (data not shown).

\section{Inhibition of cancer invasion in collagen matrices by EGCG}

When cultured atop collagen gels, SCC9, SCC25, and HeLa cells formed confluent monolayers that remained confined to the surface of the underlying gel for the entire culture period regardless of the presence of EGCG or 5-aza-dC. We also did not 

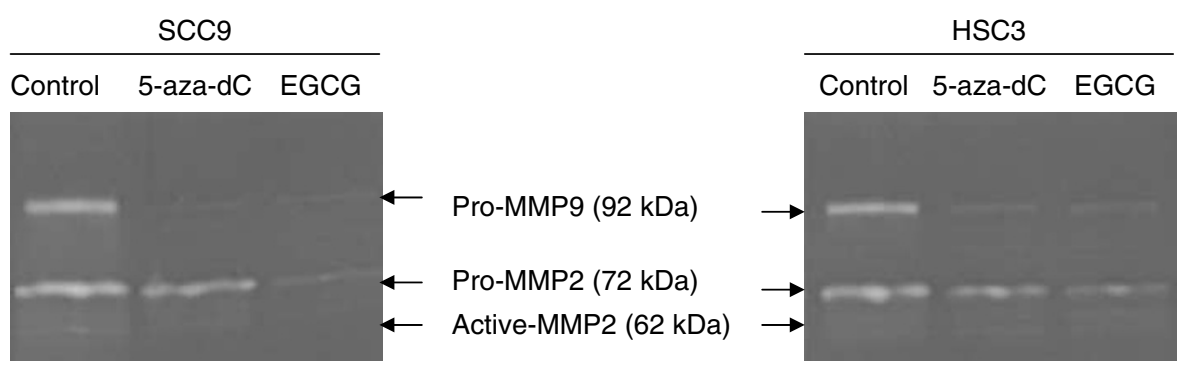

Figure 4 Gelatin zymography analysis. Clear zones of proform and active MMP-2 (72 and $62 \mathrm{kDa}$ ) and relatively weaker MMP-9 bands ( $92 \mathrm{kDa}$ proform and $82 \mathrm{kDa}$ active form) that attenuated following the $50 \mu \mathrm{M}$ EGCG or 5-aza-dC $8.7 \mu \mathrm{M}$ treatment for 6 days in SCC9 and HSC3 cells.

Control

A

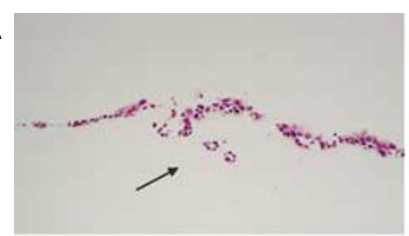

B

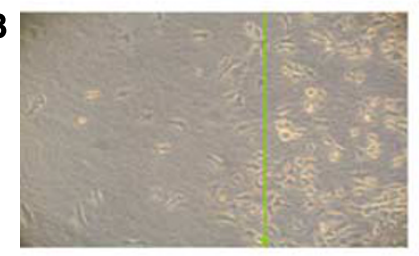

C

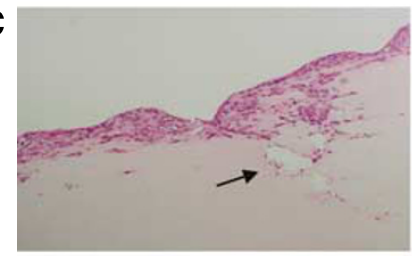

D

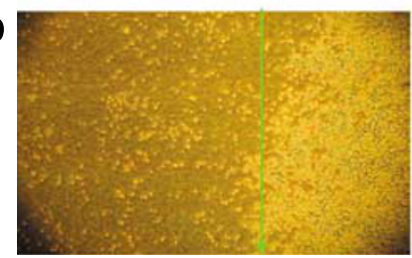

$50 \mu \mathrm{M}$ EGCG
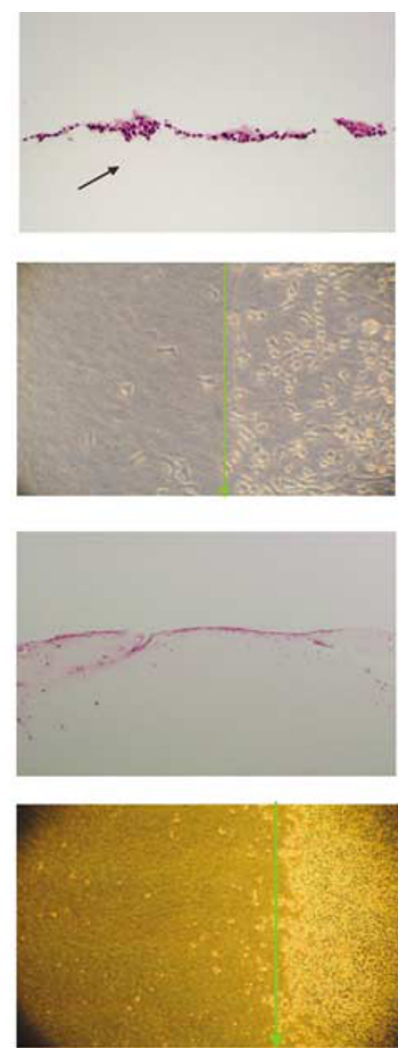

Figure 5 Collagen gel invasion model. Treatment of EGCG for 6 days inhibits cancer invasion in collagen model in HSC3 cells. (A) The collagen gel was collected and fixed in 10\% formalin, embedded in paraffin, stained with haematoxylin and eosin and examined for cancer cell invasion. Treatment with EGCG significantly inhibits invasion in collagen model for 6 days (Arrow is showing an invasive foci). (B) Cell migration ability was suppressed in the presence of EGCG for 6 days. Cells atop collagen gels with surfaces were partially covered by glass coverslips $(I \times 2 \mathrm{~cm})$. When the cells reach confluence, the glass fragments were removed, leaving a cell-free area on the gel. The distances migrated across the gels were observed $24 \mathrm{~h}$ later using inverted microscope. (C) Inhibition of cell invasion by EGCG in HSC3 cells for 14 days. (D) The ability of cancer cells to migrate from the edge towards centre of the uncovered gel in HSC3 cells cultured with EGCG were decreased as compared to control on day 14 (after $24 \mathrm{~h}$ of removing the cover slips) ( $\times 100$ magnification). The arrows show the margin of the uncovered area on the gel.

observe the significant invasion in the SCC9 and SCC25 cells. However, treatment with EGCG significantly inhibits cancerinvasive ability in collagen model in HSC4 and HSC3 cancer cell lines (Figure 5A-D). During 7 days treatment with EGCG, HSC3 and HSC4 cells proliferated at a lower rate compared with those of control or 5 -aza-dC treated cells. Although treatment with $50 \mu \mathrm{M}$ EGCG caused some damaged cells with vesicles, signs of toxicity were not apparent at lower doses.

Our results indicated that treatment with $50 \mu \mathrm{M}$ EGCG significantly inhibited cancer invasion in a three-dimensional collagen model. Furthermore, EGCG or 5-aza-dC significantly blocked cancer invasion in HSC3 cells by decreasing the mean number of invasive foci/field $(P<0.0001$ and $P<0.00001$, respectively). Results are shown as the mean number of invasive foci \pm 1 s.d. in five randomly selected fields in HSC3 cells treated with 5-aza-dC, EGCG and control $(6 \pm 2$ foci, $11.4 \pm 2.7$ foci, and $26.4 \pm 3.8$ foci, respectively). Interestingly, regarding cell migration and depth of invasion, EGCG significantly inhibited cells to invade deeply into the collagen gel compared with control $(93 \pm 32.3 v \mathrm{~s}$ $191.2 \pm 33.7 \mu \mathrm{m}, P<0.005)$ as well as suppressed the cells migrating across the gels surface (Figure 5B, D and 6A, B). Similar effects were also observed in HSC4 cell line (Table 1).

In the presence of EGCG, HSC3 and HSC4 cells cultured atop collagen gels for 6 days displayed widespread but shallow foci of invasion. In contrast, control cells (EGCG-free medium) invaded and generated large and deep pits extending well in the collagen matrix. After 14 days, HSC3 cells cultured in the absence of EGCG formed an aggressive invasion and proliferation (with stratified 5-6 cell layers) whereas invasion of HSC3 cells treated with EGCG was markedly inhibited and only generated pits underlying collagen gels (Figure 5C and D).

\section{DISCUSSION}

In the present study, we report that EGCG, a major component of green tea, may enhance RECK expression by reversal of hypermethylation of $R E C K$ promoter and inhibit MMP activities as well as cancer cell invasion in OSCC cell lines. Recent studies have also shown that RECK methylation is associated with increase of metastasis and invasion in human cancers (Chang et al, 2006, 2007; Cho et al, 2007).

Our findings implied that the hypermethylation of $R E C K$ is associated with a low level of mRNA expression in oral squamous cell carcinoma cell lines. Of these, SCC9 and SCC25 cell lines were partially methylated whereas HSC4 or HSC3 cells were almost completely methylated. The results showed that treatment of oral cancer cells with EGCG partially reversed the hypermethylation status of the RECK gene and significantly enhanced the expression level of RECK mRNA. EGCG has been reported to reverse hypermethylation and reactivate several tumour suppressor genes in human oesophageal squamous cell carcinoma cell lines at doses from $20 \mu \mathrm{M}$ (Fang et al, 2003) by nested two-stage MSP. However, present oral cancer cell lines appear to be less susceptible to a demethylation effect by EGCG. Additional work is needed to determine whether different genes respond similarly or differently to the EGCG treatment in different cell lines under various treatment conditions. 
A
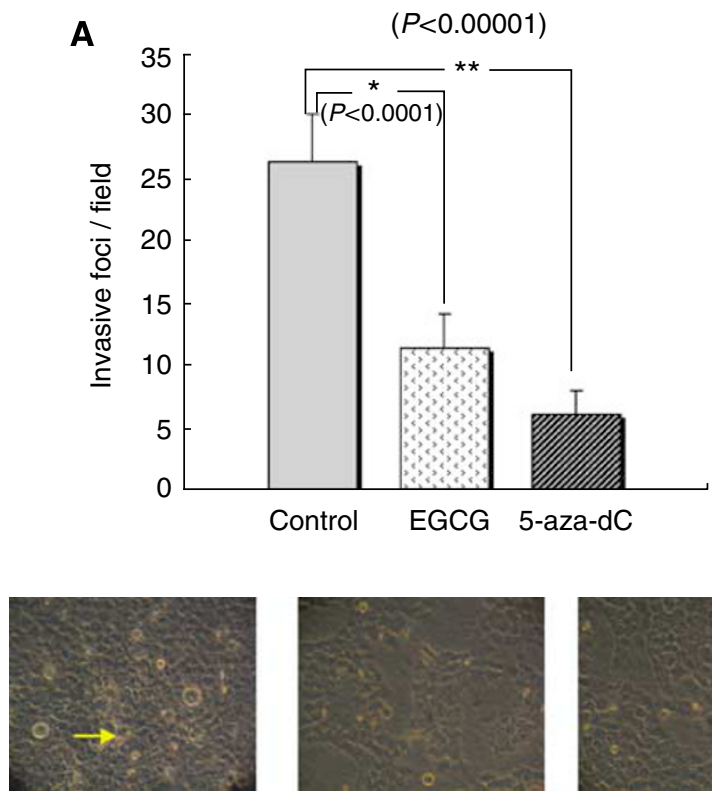

Control

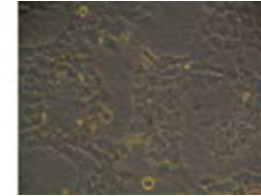

$8.7 \mu \mathrm{m}$ 5-aza-dC

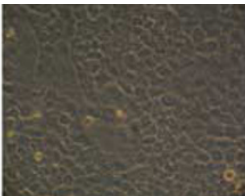

$50 \mu \mathrm{M}$ EGCG

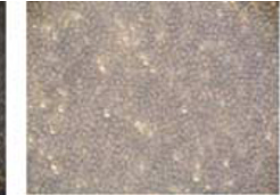

Control
B
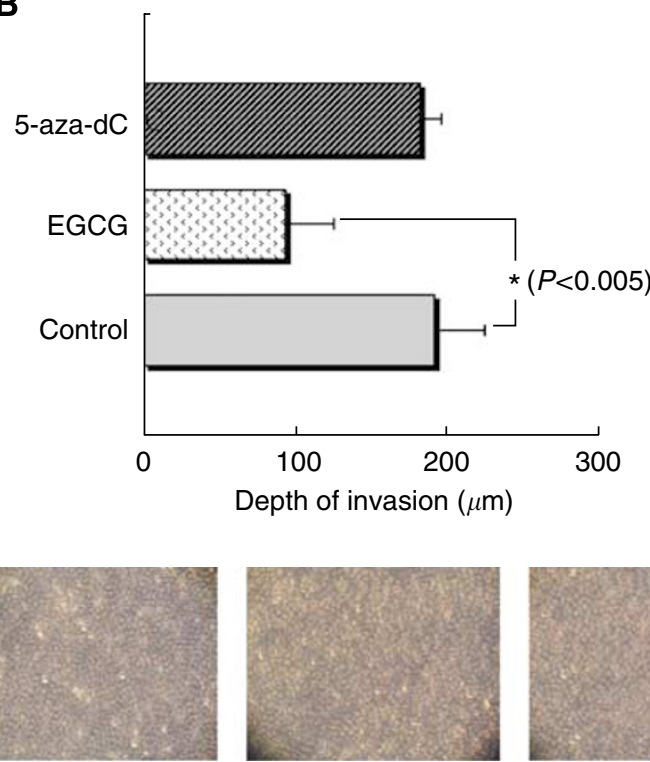

$8.7 \mu \mathrm{m}$ 5-aza-dC

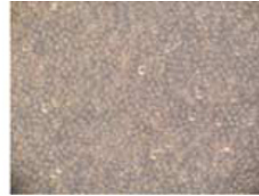

$50 \mu \mathrm{m}$ EGCG

On top of collagen gels

Focal plane located $200 \mu \mathrm{M}$ below the top of collagen $(\times 100)$

Figure 6 Invasive foci formation and invasion depth of cancer cells were inhibited by EGCG. (A) On top of collagen gels ( $\times 200$ magnification) EGCG or 5 -aza-dC significantly blocked cancer invasion in HSC3 cells by decreasing the mean number of invasive foci/field by $t$-test. Results are shown as the mean number of invasive foci \pm I s.d. in five randomly selected fields (6 days). (B) Focal plane located $200 \mu \mathrm{m}$ below the top of collagen ( $\times$ I 00 magnification) 6 days after addition of HSC3 cells to gels, the depths of cell invasion of cells that had invaded the gel were significantly blocked in cells treated with EGCG. Similar results were observed with HSC4 cell line (not shown).

Table I Mean number of invasive foci per field and depth of invasion in HSC3 and HSC4 cancer cell lines after treatment with $50 \mu \mathrm{M}$ EGCG or $8.7 \mu \mathrm{M}$ 5 -aza-dC for 6 days

\begin{tabular}{|c|c|c|c|c|c|c|}
\hline Cell line & \multicolumn{3}{|c|}{ Number of invasive foci per field mean \pm s.d. } & \multicolumn{3}{|c|}{ Depth of invasion mean \pm s.d. $(\mu \mathrm{m})$} \\
\hline $\begin{array}{l}\mathrm{HSC} 3 \\
\mathrm{HSC} 4\end{array}$ & $\begin{array}{l}26.4 \pm 3.8 \\
17.6 \pm 2.9\end{array}$ & $\begin{array}{l}11.4 \pm 2.7^{\mathrm{a}} \\
10.2 \pm 0.8^{\mathrm{d}}\end{array}$ & $\begin{array}{r}6.0 \pm 2.0^{b} \\
10.6 \pm 3.6^{c}\end{array}$ & $\begin{array}{l}191.0 \pm 33.7 \\
234.6 \pm 27.9\end{array}$ & $\begin{array}{r}93.0 \pm 32.3^{c} \\
|80.4 \pm 16 .|^{a}\end{array}$ & $\begin{array}{l}182.4 \pm 13.2 \\
206.4 \pm 25.9\end{array}$ \\
\hline
\end{tabular}

${ }^{a} P<0.0000$ I; ${ }^{b} P<0.0001 ;{ }^{c} P<0.001 ;{ }^{d} P<0.005$ when compared with control by the Student's $t$-test.

EGCG has been shown to affect MMP activity both directly and indirectly, in particular MMP-2 at relatively low doses $(10-20 \mu \mathrm{M})$. EGCG has been reported to inhibit activating protein-1 (AP-1) that regulates MMP expression. In another way, EGCG could also inhibit the proMMP-2 protein secretion by perturbing the intracellular vesicular trafficking (Oh et al, 2004; Khan et al, 2006). However, our data demonstrate that OSCC cell lines-derived MMP-2 and MMP-9 were inhibited at $50 \mu \mathrm{M}$ of EGCG treatment. Previous studies showed that restored expression of RECK in malignant cells resulted in suppression of invasive activity with concomitant decrease in the secretion of MMPs (Takahashi et al, 1998; Okabe et al, 1999; Liu et al, 2003; Noda et al, 2003). Treatment with EGCG, HSC3 and HSC4 cells cultured on top of collagen gels produced widespread but shallow foci of invasion whereas control cells (EGCG-free medium) invaded and generated large and deep pits extending well in the collagen matrix. This could be because of the ability to regulate MMPs by RECK restored expression. Earlier study has shown that stimulated RECK expression significantly caused downregulation of MMP-2 and MMP-9 activities (Takahashi et al, 1998; Liu et al, 2003; Oh et al, 2004). In experimental systems, cellular invasion is reduced by the presence of endogenous tissue inhibitors of MMPs (TIMPs) and RECK. Recently, TIMP-2 has been reported to enhance expression of RECK through Rap1 signalling resulting in an indirect, time-dependent inhibition of cell migration (Oh et al, 2004). Our findings suggest that EGCG and 5-aza-dC may act simultaneously through different target proteins such as TIMPs and RECK to suppress invasion. Further study is needed to define the extent of contribution of RECK on MMPs to the suppression of cell-invasive behaviours.

The results support the conclusion that EGCG plays a crucial role in inhibiting cell invasion of a collagen model. EGCG significantly suppressed cancer-invasive ability in oral cancer cell lines by decreasing the number of invasive foci and depth of invasion as strong as classical DNMT inhibitor, 5-aza-dC. Oral administration of green tea has been reported to inhibit tumour genesis in different organs and multiple mechanisms may be involved (Jung and Ellis, 2000; Khan et al, 2006; Chiang et al, 2006; Okabe et al, 1999). Importantly, these effects of EGCG have been shown to be selective for cancer cells, as normal cells were not affected by this treatment (Khan et al, 2006).

The present study indicated that the effective dose of EGCG in inhibiting cancer invasion and migration is at $50 \mu \mathrm{m}$. At a 
concentration of $20 \mu \mathrm{m}$ or lower, EGCG did not significantly affect cancer invasion or migration of the cells. It is achievable in the oral cavity (in saliva) after drinking green tea and perhaps in the stomach, esophagus and the intestines where there is direct contact between EGCG and the epithelial cells (Fang et al, 2003). This effective concentration is variable in different organs and the DNMT inhibition would depend on the systemic bioactivities and the bioavailability of EGCG in a particular organ site. Inhibition of DMNT is expected to prevent hypermethylation; however, severe inhibition of DNMT activity may cause DNA hypomethylation, genomic instability and other disorders (Szyf et al, 2004; Wilson et al, 2007). The effects of EGCG in vitro have been obtained with relatively high concentrations than observed in the plasma or tissues of animals or in human plasma after the administration of green tea or EGCG (Masuda et al, 2001; Khan et al, 2006). Therefore, it is not clear whether the activities observed with high EGCG concentrations in cell lines can be observed in vivo. More comprehensive studies in animal models and humans are needed to determine the optimal doses and side effects of EGCG.

In conclusion, our findings raise the possibility that EGCG could inhibits cancer cell invasion through reversal of hypermethylation status of RECK and downregulation of MMP-2 and MMP-9. Our data together with earlier studies indicate that EGCG as a natural demethylating agent could be a promising therapeutic strategy for the development of combination chemopreventive/chemotherapeutic approaches in oral cancer treatment. Additional investigations are required to fully elucidate the molecular mechanisms by which green tea constituents, and EGCG in particular, inhibit tumour invasion and metastasis.

\section{REFERENCES}

Benelli R, Vene R, Bisacchi D, Garbisa S, Albini A (2002) Anti-invasive effects of green tea polyphenol epigallocatechin-3-gallate (EGCG), a natural inhibitor of metallo and serine proteases. Biol Chem 383: $101-105$

Chang HC, Cho CY, Hung WC (2006) Silencing of the metastasis suppressor RECK by RAS oncogene is mediated by DNA Methyltransferase 3b-induced promoter methylation. Cancer Res 66: 8413-8420

Chang HC, Cho CY, Hung WC (2007) Downregulation of RECK by promoter methylation correlates with lymph node metastasis in nonsmall cell lung cancer. Cancer Sci 98: 169-173

Chiang WC, Wong YK, Lin SC, Chang KW, Liu CJ (2006) Increase of MMP13 expression in multi-stage oral carcinogenesis and epigallocatechin-3gallate suppress MMP-13 expression. Oral Dis 12: 27-33

Cho CY, Wang JH, Chang HC, Chang CK, Hung WC (2007) Epigenetic inactivation of the metastasis suppressor RECK enhances invasion of human colon cancer cells. J Cell Physiol 213: 65-69

Chung FL, Schwartz J, Herzog CR, Yang YM (2003) Tea and cancer prevention: studies in animals and humans. J Nutr 133: 3268-3274

Fang MZ, Wang YW, Ai N, Hou Z, Sun Y, Lu H, Welsh W, Yang CS (2003) Tea polyphenol (-)-epigallocatechin-3-gallate inhibits DNA methyltransferase and reactivates methylation-silenced genes in cancer cell lines. Cancer Res 63: 7563-7570

Fassina G, Vene R, Morini M, Minghelli S, Benelli R, Noonan DM, Albini A (2004) Mechanisms of inhibition of tumor angiogenesis and vascular tumor growth by epigallocatechin-3-gallate. Clin Cancer Res 10: $4865-4873$

Furumoto K, Arii S, Mori A, Furuyama H, Gorrin Rivas MJ, Nakao T, Isobe N, Murata T, Takahashi C, Noda M, Imamura M (2000) RECK gene expression in hepatocellular carcinoma: correlation with invasion-related clinicopathological factors and its clinical significance. Hepatology 33: $189-195$

Ha PK, Califano JA (2006) Promoter methylation and inactivation of tumour-suppressor genes in oral squamous-cell carcinoma. Lancet Oncol 7: $77-82$

Hase T, Kawashiri S, Tanaka A, Nozaki S, Noguchi N, Kato K, Nakaya H, Nakagawa K, Yamamoto E (2006) Fibroblast growth factor-2 accelerates invasion of oral squamous cell carcinoma. Oral Sci Int 3: 1-9

Hellebrekers DM, Griffioen AW, van Engeland M (2007) Dual targeting of epigenetic therapy in cancer. Biochim Biophys Acta 1775: 76-91

Hotary K, Allen E, Punturieri A, Yana I, Weiss SJ (2000) Regulation of cell invasion and morphogenesis in a three-dimensional type I collagen matrix by membrane-type matrix metalloproteinases 1, 2, and 3 . J Cell Biol 149: 1309-1323

Ju J, Hong J, Zhou JN, Pan Z, Bose M, Liao J, Yang GY, Liu YY, Hou Z, Lin Y, Ma J, Shih WJ, Carothers AM, Yang CS (2005) Inhibition of intestinal tumorigenesis in $A p c^{\mathrm{min} /+}$ mice by (-)-epigallocatechin-3-gallate, the major catechin in green tea. Cancer Res 65: 10623-10631

Jung YD, Ellis LM (2000) Inhibition of tumour invasion and angiogenesis by epigallocatechin gallate (EGCG), a major component of green tea. Int J Exp Path 82: 309-316

Kato K, Hara A, Kuno T, Kitaori N, Huilan Z, Mori H, Toida M, Shibata T (2005) Matrix metalloproteinases 2 and 9 in oral squamous cell carcinomas: manifestation and localization of their activity. $J$ Cancer Res Clin Oncol 131: 340 - 346

Khan N, Afaq F, Saleem M, Ahmad N, Mukhtar H (2006) Targeting multiple signaling pathways by green tea polyphenol (-)-epigallocatechin-3gallate. Cancer Res 66: 2500-2505

Lambert JD, Yang CS (2003) Mechanisms of cancer prevention by tea constituents. J Nutr 133: 3262-3267

Liebersbach BF, Sanderson RD (1994) Expression of Syndecan-1 inhibits cell invasion in to type I collagen. J Biol Chem 269: 20013-20019

Liu LT, Chang HC, Chiang LC, Hung WC (2003) Histone deacetylase inhibitor up-regulates RECK to inhibit MMP-2 activation and cancer cell invasion. Cancer Res 63: 3069-3072

Lund AH, van Lohuizen M (2004) Epigenetics and cancer. Genes Dev 18: $2315-2335$

Masuda M, Suzui M, Weinstein IB (2001) Effects of epigallocatechin-3gallate on growth, epidermal growth factor receptor signaling pathways, gene expression, and chemosensitivity in human head and neck squamous cell carcinoma cell lines. Clin Cancer Res 7: 4220-4229

Noda M, Oh J, Takahashi R, Kondo S, Kitayama H, Takahashi C (2003) RECK: a novel suppressor of malignancy linking oncogenic signaling to extracellular matrix remodeling. Cancer Metastasis Rev 22: $167-175$

Oh J, Seo DW, Diaz T, Wei B, Ward Y, Ray JM, Morioka Y, Shi S, Kitayama H, Takahashi C, Noda M, Stetler-Stevenson WG (2004) Tissue inhibitors of metalloproteinase 2 inhibits endothelial cell migration through increased expression of RECK. Cancer Res 64: $9062-9069$

Oh J, Takahashi R, Kondo S, Mizoguchi A, Adachi E, Sasahara RM, Nishimura S, Imamura Y, Kitayama H, Alexander DB, Ide C, Horan TP, Arakawa $\mathrm{T}$, Yoshida $\mathrm{H}$, Nishikawa $\mathrm{S}$, Itoh $\mathrm{Y}$, Seiki $\mathrm{M}$, Itohara $\mathrm{S}$, Takahashi C, Noda M (2001) The membrane-anchored MMP inhibitor RECK is a key regulator of extracellular matrix integrity and angiogenesis. Cell 107: 789-800

Okabe S, Ochiai Y, Aida M, Park K, Kim SJ, Nomura T, Suganuma M, Fujiki H (1999) Mechanistic aspects of green tea as a cancer preventive: Effect of components on human stomach cancer cell lines. Jpn J Cancer Res 90: $733-739$

Sasahara RM, Brochado SM, Takahashi C, Oh J, Maria-Engler SS, Granjeiro JM, Noda M, Sogayar MC (2002) Transcriptional control of the RECK metastasis/angiogenesis suppressor gene. Cancer Detection Prev 26: $435-443$

Shaw R (2006) The epigenetics of oral cancer. Int J Oral Maxillofac Surg 35: $101-108$

Shaw RJ, Hall GL, Lowe D, Bowers NL, Liloglou T, Field JK, Woolgar JA, Risk JM (2007) CpG island methylation phenotype (CIMP) in oral cancer: Associated with a marked inflammatory response and less aggressive tumour biology. Oral Oncol 43: 878-886

Simizu S, Takagi S, Tamura Y, Osada H (2005) RECK-mediated suppression of tumor cell invasion is regulated by glycosylation in human tumor cell lines. Cancer Res 65: 7455-7461

Song SY, Son HJ, Nam E, Rhee JC, Park C (2006) Expression of reservesioninducing-cystein-rich protein with Kazal motifs (RECK) as prognostic indicator in gastric cancer. Eur J Cancer 42: 101 - 108 
Stresemann C, Brueckner B, Musch T, Stopper H, Lyko F (2006) Functional diversity of DNA methyltransferase inhibitors in human cancer cell lines. Cancer Res 66: 2794-2800

Szyf M, Pakneshan P, Rabbani SA (2004) DNA demethylation and cancer: therapeutic implications. Cancer Lett 211: 133-143

Takahashi C, Sheng Z, Horan TP, Kitayama H, Maki M, Hitomi K, Kitaura Y, Takai S, Sasahara RM, Horimoto A, Ikawa Y, Ratzkin BJ, Arakawa T,
Noda M (1998) Regulation of matrix metalloproteinase-9 and inhibition of tumor invasion by the membrane-anchored glycoprotein RECK. Proc Natl Acad Sci USA 95: 13221 - 13226

Wilson AS, Power BE, Molly PL (2007) DNA hypomethylation and human diseases. Biochim Biophys Acta 1775: $138-162$

Yang CS, Maliakal P, Meng X (2002) Inhibition of carcinogenesis by tea. Annu Rev Pharmacol Toxicol 42: $25-54$ 